\title{
Studies on retinitis pigmentosa in man. I. Taurine and blood platelets
}

\author{
M. J. VOADEN, A. A. HUSSAIN, AND I. P. R. CHAN \\ From the Department of Visual Science, Institute of Ophthalmology, University of London, Judd Street, London \\ WC1H $9 Q S$
}

SUMMARY Platelets from patients with various genetically determined forms of photoreceptor dystrophy and with the clinical manifestations of retinitis pigmentosa (RP) have been studied. Variations in protein content have been observed, with less than normal in multiplex RP (probably autosomal recessive inheritance) and more in platelets from patients with autosomal dominant RP. This may reflect variation in platelet size or in surface adsorption of plasma proteins. Several patients presented with thrombocytopenia, the mean platelet count for X-linked hemizygote patients, as a group, being significantly lower than normal. Accumulation of ${ }^{3} \mathrm{H}$-taurine has been studied in platelets incubated in $\mathrm{Ca}^{2+}$-free Krebs bicarbonate medium containing $1.0 \mu \mathrm{M}$ or $60 \cdot 0 \mu \mathrm{M}$ taurine, and in autologous plasma. Although, in general, platelets from patients with RP showed normal taurine uptake, the capacity of the higher affinity carrier was increased in patients with X-linked hemizygote and multiplex disease. In contrast, plasma from patients with X-linked hemizygote RP reduced the platelet tissue to medium ratio, established for ${ }^{3} \mathrm{H}$-taurine uptake, by $20 \%$. More studies are needed to ascertain whether this represents a reduced taurine uptake or is caused by an increased concentration of taurine in the plasma.

The sulphonic amino acid taurine exists in a very high concentration in retinal photoreceptor cells. ${ }^{12}$ Its function(s) is unknown, but photoreceptors degenerate in cats maintained on a taurine-free diet. ${ }^{3}$ Taurine may therefore be essential for photoreceptor viability, and blood may be an important source of taurine for the retina. Entry into the tissue is modulated by the retinal pigment epithelium (RPE), which has an active high-affinity uptake system for it. ${ }^{4-6}$ The taurine is then passed by exchange or net uptake, according to nutritional status, ${ }^{7}$ into the retina.

Patients with various hereditary diseases which lead to degeneration of photoreceptor cells have been reported to have normal plasma taurine concentrations. ${ }^{8}$ However, it is not known if entry of the amino acid into the retina is efficient. Athough this cannot be studied directly in vivo, it is possible to investigate similar systems in more readily accessible tissues. For example, blood platelets are rich in taurine and possess a high-affinity uptake system for it, resembling that found in the RPE. ${ }^{9}$ It has been reported that taurine uptake is lower than normal in platelets from

Correspondence to Dr Mary J. Voaden. patients with retinitis pigmentosa (RP). ${ }^{1011}$ As the majority of people included in this study had no known affected relatives, RP could have arisen either from inheritance of autosomal recessive genes or as the result of a spontaneous genetic mutation or from a nongenetic cause. There is the likelihood therefore of heterogeneity within the group.

Several distinct inheritance patterns of RP are recognised. They include autosomal dominant, Xchromosome-linked (X-hemizygote), and autosomal recessive. The last is most clearly distinguished when brothers and sisters express the disease but there are no other affected relatives, a category referred to by $\mathrm{Jay}^{12}$ as mixed multiplex. We shall use this terminology, referring also to RP patients with no known affected relatives as simplex. ${ }^{12}$

In the present study we have investigated taurine uptake by platelets obtained from patients with inheritance patterns characteristic of the above categories. It must be emphasised, however, that this does not necessarily mean homogeneous groups. Measurements have been made in autologous plasma, and in $\mathrm{Ca}^{2+}$-free Krebs bicarbonate medium containing 1.0 or $60.0 \mu \mathrm{M}^{3} \mathrm{H}$-taurine. With the former the 
rate of entry will reflect activity of the 'higher-affinity' carrier, ${ }^{9}$ whereas the latter may more closely simulate the levels found in plasma as it is normally prepared, that is, $30-150 \mu \mathrm{M} \cdot{ }^{813}$ Some of the data have been presented in a preliminary communication. ${ }^{14}$

\section{Materials and methods}

In general, patients who participated attended the Genetic and Electrodiagnostic Clinics of Moorfields Eye Hospital, London, where the category and extent of retinal dystrophy were defined genetically, clinically, and, where possible, by psychophysical and electrophysiological tests. Their age range was $15-75$ years and that of apparently normal volunteers 19-64 years.

Blood $(20 \mathrm{ml})$ was obtained by venepuncture and added to tubes containing potassium EDTA (final concentration $0.25 \%$ ) to prevent coagulation. Approximately $1.0 \mathrm{~h}$ later it was centrifuged in $2 \times 10$ $\mathrm{ml}$ aliquots at $300 \mathrm{~g}$ for $15 \mathrm{~min}$ at room temperature. The supernatants, composed of platelet-rich plasma (PRP), were then drawn off and pooled. Aliquots were then either used immediately for assessment of taurine uptake, after the addition of trace amounts of ${ }^{3} \mathrm{H}$-taurine, or centrifuged at $900 \mathrm{~g}$ for $10 \mathrm{~min}$. No haemolysis was evident.

Resultant pellets of platelets were resuspended to a volume equivalent to that of the original PRP, in $\mathrm{Ca}^{2+}$-free Krebs bicarbonate medium containing $3 \cdot 0$ mM EDTA ${ }^{9}$-hereafter referred to as KRB. $1 \mathrm{ml}$ portions were then incubated for 20 min with 1.0 or
$60.0 \mu \mathrm{M}{ }^{3} \mathrm{H}$-taurine $(0.25 \mu \mathrm{Ci} / \mathrm{ml}$, added in a volume of $20 \mu \mathrm{l}$ ) at $37^{\circ} \mathrm{C}$ or $0^{\circ} \mathrm{C}$, in an atmosphere of $95 \% 0_{2}$ : $5 \% \mathrm{CO}_{2} .{ }^{3} \mathrm{H}$-taurine $(18 \mathrm{Ci} / \mathrm{mmol} ; 1 \mathrm{mCi} / \mathrm{ml})$ was obtained from Amersham International Ltd, England. Packard 'mini' counting vials were used as incubation vessels. Ten-minute incubations were also included in many of the tests to establish linearity of uptake of the radioactivity in all the groups studied. 'Uptake' was stopped by placing the tubes in ice, and the platelets were then recovered by centrifuging at $1800 \mathrm{~g}$ for 10 $\min$ at $4^{\circ} \mathrm{C}$.

Ten $\mu \mathrm{l}$ of medium was removed at the beginning and end of the incubation, the radioactivity counted, and a mean of the 2 used to assess tissue/medium (T/M) ratios. The remaining medium was poured from the tube, which was then drained on filter paper, and the sides were swabbed with small portions of filter paper, held with fine forceps, to remove adhering droplets of medium. In some estimations the platelets were then washed once with fresh taurinefree medium. Although this lowered the background level of ${ }^{3} \mathrm{H}$-taurine, it made no difference to the final results. Triton X-100 $(0.5 \mathrm{ml} 10 \% \mathrm{v}: \mathrm{v}$, aqueous solution) was added to solubilise the tissue, followed 30 min later by $4.5 \mathrm{ml}$ scintillation fluid. Radioactivity was counted on a Packard 3375 liquid scintillation spectrophotometer.

Platelet counts were done on whole blood and also on aliquots of PRP, and protein was estimated in known aliquots of the platelet/KRB mixture. ${ }^{15}$ The standard for this was bovine serum albumin.

Platelet wet weights were estimated from the pro-

Table $1{ }^{3} \mathrm{H}$-taurine uptake by platelets from patients with retinitis pigmentosa

\begin{tabular}{|c|c|c|c|}
\hline \multirow[t]{3}{*}{ Patient classification } & \multicolumn{3}{|c|}{ Taurine uptake ( $T / M$ ratio) } \\
\hline & \multicolumn{2}{|c|}{$\mathrm{Ca}^{2+}$-free Krebs bicarbonate medium } & \multirow[t]{2}{*}{ Autologous plasma } \\
\hline & $1 \cdot 0 \mu M$ taurine & $60 \cdot 0 \mu M$ taurine & \\
\hline $\begin{array}{l}\text { 1. 'Normal' } \\
\text { 2. Autosomal dominant } \\
\text { 3. Cone-rod dystrophy } \\
\text { 4. X-linked hemizygote } \\
\text { 5. X-linked heterozygote } \\
\text { 6. Multiplex } \\
\text { 7. Simplex }\end{array}$ & $\begin{array}{l}6 \cdot 3 \pm 0 \cdot 4(28) \\
6 \cdot 2 \pm 0 \cdot 3(25) \\
7 \cdot 7 \pm 1 \cdot 2(5) \\
8 \cdot 0 \pm 0 \cdot 7(14)^{*} \\
5 \cdot 7 \pm 0 \cdot 5(11) \\
8 \cdot 5 \pm 0 \cdot 6(10)^{* *} \\
7 \cdot 2 \pm 0 \cdot 6(17)\end{array}$ & $\begin{array}{l}3 \cdot 0 \pm 0 \cdot 3(15) \\
3 \cdot 3 \pm 0 \cdot 2(18) \\
3 \cdot 0 \pm 0 \cdot 3(5) \\
3 \cdot 4 \pm 0 \cdot 3(11) \\
2 \cdot 6 \pm 0 \cdot 4(9) \\
3 \cdot 8 \pm 0 \cdot 4(9) \\
3 \cdot 4 \pm 0 \cdot 2(15)\end{array}$ & $\begin{array}{l}5 \cdot 4 \pm 0 \cdot 2(50) \\
4 \cdot 9 \pm 0 \cdot 3(35) \\
- \\
4 \cdot 3 \pm 0 \cdot 3(15)^{* * *} \\
5 \cdot 1 \pm 0 \cdot 5(12) \\
5 \cdot 6 \pm 0 \cdot 5(10) \\
5 \cdot 2 \pm 0 \cdot 5(18)\end{array}$ \\
\hline \multicolumn{4}{|c|}{$\begin{array}{l}{ }^{*} \mathrm{p}<0 \cdot 05 ;{ }^{* *} \mathrm{p}<0 \cdot 02 ;{ }^{* * *} \mathrm{p}<0 \cdot 01 \text { when compared with total control group, } \mathrm{p}<0 \cdot 02 \text { when compared } \\
5 \cdot 4 \pm 0 \cdot 3(32) \text {. } \\
\text { Results are expressed as the mean } \pm \mathrm{SEM} \text {. The number of estimations is shown in brackets. } \\
\text { 1. Apparently healthy volunteers. } \\
\text { 2. Males and/or females affected in more than one generation. } \\
\text { 3. Family group with autosomal dominant cone-rod dystrophy with early loss of central visual acuity. } \\
\text { 4. X-chromosome-linked RP: affected males. } \\
\text { 5. Female "carriers' of } 4 \text {. } \\
\text { 6. Sibling(s) express the disease; no other known affected relatives. } \\
\text { 7. No known relatives with the disease. }\end{array}$} \\
\hline
\end{tabular}


Table 2 Platelet numbers, and protein content, in patients with retinitis pigmentosa

\begin{tabular}{llcc}
\hline Patient classification ${ }^{\dagger}$ & $\begin{array}{l}\text { Whole blood platelet count } \\
\left(X 10^{\circ} / \text { litre }\right)\end{array}$ & $\begin{array}{l}\text { Thrombocytopaenia } \ddagger \\
(\%)\end{array}$ & $\begin{array}{l}\text { Platelet protein } \\
\left(\mu g \text { protein } / 10^{\circ}\right) \S\end{array}$ \\
\hline 'Normal' & $217 \pm 8(45)$ & 2 & $2 \cdot 8 \pm 0 \cdot 1(42)$ \\
Autosomal dominant & $198 \pm 9(36)$ & 22 & $3 \cdot 4 \pm 0 \cdot 2(28)^{* *}$ \\
Cone-rod dystrophy & $162 \pm 13(5)^{*}$ & 20 & $5 \cdot 3 \pm 0 \cdot 6(5)^{* * *}$ \\
X-linked hemizygote & $154 \pm 11(15)^{* * *}$ & 47 & $3 \cdot 0 \pm 0 \cdot 2(12)$ \\
X-linked heterozygote & $193 \pm 15(15)$ & 17 & $3 \cdot 3 \pm 0 \cdot 2(12)$ \\
Multiplex & $208 \pm 11(10)$ & 24 & $2 \cdot 2 \pm 0 \cdot 1(9)^{*}$ \\
Simplex & $185 \pm 14(17)$ & $3 \cdot 3 \pm 0 \cdot 4(11)$ \\
\hline
\end{tabular}

${ }^{*} \mathrm{p}<0.05 ;{ }^{* *} \mathrm{p}<0.01 ;{ }^{* * *} \mathrm{p}<0.001$.

Results are expressed as the mean \pm SEM. The number of estimations is shown in brackets.

tSee Table 1 for definitions.

$\ddagger \%$ with platelet counts of $140 \times 10^{9} / 1$ or below.

$\S$ Refers only to platelets remaining in plasma after the initial centrifugation.

tein values by assuming a $10 \%$ protein content, and, for calculations of T/M ratios, $1.0 \mathrm{mg}$ wet weight was taken as equivalent to $1 \cdot 0 \mu \mathrm{l}$ incubation medium.

\section{Results}

A preliminary study with platelets obtained from apparently healthy volunteers and incubated in KRB established that accumulation of the ${ }^{3} \mathrm{H}$-taurine (exogenous concentration $1.0 \mu \mathrm{M}$ ) was linear with time for at least $60 \mathrm{~min}$. In addition, a MichaelisMenten plot of 'uptakes', with ${ }^{3} \mathrm{H}$-taurine concentrations ranging from 1 to $1000 \mu \mathrm{M}$ (9 concentrations, 20 min incubations), and with zero 'uptakes' subtracted, yielded evidence for a 2-carrier system with the following kinetic parameters: $\mathrm{Km}_{1} 8 \mu \mathrm{M}$ and $\mathrm{Vmax}_{1}$ $0.025 \mathrm{nmol}$ taurine $/ \mathrm{min} / \mathrm{mg}$ protein $(3.5 \mathrm{nmol} / \mathrm{min} / \mathrm{ml}$ packed cells); $\mathrm{Km}_{2} 200 \mu \mathrm{M}$ and $\mathrm{Vmax}_{2} 0 \cdot 143 \mathrm{nmol} /$ taurine $/ \mathrm{min} / \mathrm{mg}$ protein $(20 \mathrm{nmol} / \mathrm{min} / \mathrm{ml}$ packed cells). Therefore at an exogenous taurine concentration of $1.0 \mu \mathrm{M}$ approximately $80 \%$ will move via the higher affinity carrier, whereas at $60 \mu \mathrm{M}, 60-70 \%$ will be accumulated by the lower affinity system.

Normal T/M ratios were established for ${ }^{3} \mathrm{H}$-taurine uptake by platelets from most patients regardless of the incubation medium employed (Table 1). The notable exception was the significantly lower ratio established when platelets from X-linked hemizygote patients were incubated in their own plasma, and the greater than normal uptake seen when they were incubated in KRB containing $1.0 \mu \mathrm{M}$ taurine. It would appear, therefore, that the plasma was effecting the former result. The rate of high-affinity taurine uptake was also increased in multiplex patients, although in this group the $T / M$ ratios established in autologous plasma were apparently normal.

Several of the patients included in this study had thrombocytopenia (Table 2), the mean whole blood platelet count being significantly lower than in con- trols (mixed or males only) both in X-linked hemizygotes and in a family group with autosomal dominant cone/rod dystrophy (macular dystrophy combined with peripheral outer retinal degeneration, loss of visual acuity occurring in the 1st-2nd decades of life). In the latter group the protein values obtained for the platelets retained after centrifugation suggested that they were almost double the size of those obtained from control bloods (Table 2). A slight increase in the mean protein content was also observed for platelets from other patients with autosomal dominantly inherited RP, whereas the value obtained for platelets from multiplex patients was smaller than normal.

\section{Discussion}

The results from this initial study suggest that in general platelets from patients with RP have a normal capacity for taurine uptake. The exceptions are platelets from 'X-hemizygote' and multiplex patients, where there is evidence for an increase in the capacities of their 'high-affinity' uptake systems. We do not have enough information on overall taurine homoeostasis in these patients to comment on the significance of these observations and how they might affect in-vivo situations. It is recognised that the kinetics of taurine uptake into platelets may not be the same in plasma as in $\mathrm{KRB}^{9}$ and that plasma proteins affect platelet function. ${ }^{16}$ As yet we do not know the taurine concentrations in our plasma samples. We cannot therefore assess the effects of the plasmas on the kinetics of taurine accumulation. However, it is of interest that plasma from ' $X$-hemizygote' patients reduced to below normal the $\mathrm{T} / \mathrm{M}$ ratio established by autologous platelets. This may represent a decreased taurine uptake or could be caused by an increase in the plasma concentration of taurine, and further studies are needed. Berson et al. ${ }^{8}$ found normal 
taurine levels in plasmas from 3 patients with X-linked hemizygote RP, and Arshinoff et al ${ }^{17}$ have reported an $11 \%$ reduction in the concentration of taurine in whole blood haemolysates from X-linked hemizygote patients. Published evidence does not therefore suggest increased plasma taurine levels in this group. The other possibility, that something in the plasma is affecting taurine uptake, is worthy of further consideration, since it is feasible that effects on a long-lived tissue such as the pigment epithelium might be more severe than on blood platelets with their half-life of only 9-11 days.

Apart from a reduced T/M ratio for taurine uptake in autologous plasma, platelets are also reduced in number in X-hemizygote bloods, a result that might at least in part explain the lowered concentration of taurine in whole-blood haemolysates found by Arshinoff $e t$ al. ${ }^{17}$ as platelets do contain a very high concentration of endogenous taurine. We cannot conclude that our findings represent a decreased number of platelets per unit volume of plasma, as we have also, in preliminary studies, found evidence for a raised haematocrit in these patients. Our investigations are therefore continuing.

In contrast to our present findings Airaksinen and co-workers ${ }^{1011}$ reported a significant decrease in taurine uptake by platelets obtained from a predominantly simplex group of RP patients. Endogenous platelet taurine was also lowered. In both studies results were expressed per unit platelet and might therefore have been effected by a reduction in platelet size. Although we have found a normal level of platelet protein in our present study on simplex patients, it should be noted that there was wide variation in the results we obtained, with values ranging from 2 to over $6 \mu \mathrm{g}$ protein $/ 10^{6}$ platelets. Thus the patients were possibly heterogeneous as regards RP classification. We have, however, observed a reduction in platelet protein, and possibly therefore in platelet size, in the multiplex RP patients (Table 2). Indeed if we had calculated the taurine uptake data presented here in terms of platelet numbers, we would have observed a $20 \%$ reduction belaw normal in the number of counts accumulated by the 'multiplex' platelets. Of the 10 patients studied by us 6 were mixed multiplex (brother(s) and sister(s) affected) and 2 were females with only affected sisters. It is probable, therefore, that the group contains a predominance of patients with autosomal recessive RP. If this were true also of the patients studied by Airaksinen et al. ${ }^{11}$ variation from normal in platelet size might explain the discrepancy between our findings.

The increased protein content of platelets from patients with autosomal dominantly inherited RP might relate to increased platelet size but could also be caused by increased adsorption of blood proteins on to the plasma membrane..$^{1819}$ In this instance we observed normal plasma uptakes when the taurine data were recalculated in terms of platelet numbers.

The results of the studies reported here, although raising many new questions, do show that there may be changes in blood homoeostasis in RP patients specific to the various genetic classifications of the disease. This alone would make the observations worthy of further investigation.

Many people, including members of the British Retinitis Pigmentosa Society, have provided essential background help in this study ranging from the classification of patients to the volunteering and taking of blood. We thank them all. In particular, we are grateful for the encouragement and time given by Miss Gillian Clover, Mr Michael Quinlan, Miss Lou Lyness, Professor Geoffrey Arden, and Professor Alan Bird. We thank Professor A. Garner, Department of Pathology, Institute of Ophthalmology, for allowing us to use the facilities of his Department, and his staff for their help, in the initial phase of this study, with platelet counting and general blood surveys.

The study is being supported by grants from the American Retinitis Pigmentosa Society and the Medical Research Council.

\section{References}

1 Orr HT, Cohen AI, Lowry OH. The distribution of taurine in the vertebrate retina. J Neurochem 1976; 26: 609-11.

2 Voaden MJ, Lake N, Marshall J, Morjaria B. Studies on the distribution of taurine and other neuroactive amino acids in the retina. Exp Eye Res 1977; 25: 249-57.

3 Berson EL, Hayes KC, Rabin AR, Schmidt SY, Watson G. Retinal degeneration in cats fed casein. II. Supplementation with methionine, cysteine or taurine. Invest Ophthalmol Visual Sci 1976; 15: 52-8.

4 Voaden MJ, Oraedu ACI, Marshall J, Lake N. Taurine in the retina. In: Baskin S, Koscis JJ, Schaeffer S, eds. The effects of taurine on excitable tissues. New York: Spectrum Publications, 1981: 145-60.

5 Lake N. Marshall J, Voaden MJ. The entry of taurine into the neural retina and pigment epithelium of the frog. Brain Res 1977; 128: 497-503.

6 Edwards RB. Accumulation of taurine by cultured pigment epithelium of the rat. Invest Ophthalmol Visual Sci 1977; 16: 201-8.

7 Sturman JA, Rassin DK, Hayes KC, Gaull GE. Taurine deficiency in the kitten: exchange and turnover of ${ }^{35} \mathrm{~S}$ taurine in brain, retina and other tissues. $J$ Nutr 1978: 108: 1462-76.

8 Berson EL, Schmidt SY, Rabin AR. Plasma amino acids in hereditary retinal disease: ornithine, lysine and taurine. $\mathrm{Br} J$ Ophthalmol 1976; 60: 142-7.

9 Ahtee L, Boullin DJ, Paasonen MK. Transport of taurine by normal human blood platelets. Br J Pharmacol 1974; 52: 245-51.

10 Airaksinen EM, Airaksinen MM, Sihvola P, Sihvola M, Tuovinen E. Uptake of taurine by platelets in retinitis pigmentosa. Lancet 1979 ; i: 474-5.

11 Airaksinen EM, Airaksinen MM, Sihvola P, Marnela K-M. Decrease in the uptake and concentration of taurine in blood platelets of retinitis pigmentosa patients. Metabol Pediatr Ophthalmol 1981; 5: 45-8.

12 Jay M. On the heredity of retinitis pigmentosa. Br J Ophthalmol 1982; 66: 405-16.

13 Perry TL, Hansen S. Technical pitfalls leading to errors in the quantitation of plasma amino acids. Clin Chim Acta 1969; 25: 53-8.

14 Voaden MJ, Chan IPR, Hussain AA. Taurine uptake by platelets from patients with retinitis pigmentosa. In: Clayton RM, 
Haywood J, Reading HW, Wright A, eds. Biology of normal and genetically abnormal retinas. London: Academic Press, in press.

15 Lowry OH, Rosebrough NJ, Farr AL, Randall RJ. Protein measurement with folin phenol reagent. J Biol Chem 1951; 193: 265-75.

16 Hansen MS, Bang NU. The influence of plasma proteins on human platelet metabolism. Thromb Res 1979; 14: 131-46.

17 Arshinoff SA, McCulloch JC, Macrae W, Stein AN, Marliss EB.
Amino acids in retinitis pigmentosa. Br J Ophthalmol 1981; 65: 626-30.

18 Mueller-Eckhardt C, Kayser W, Mersch-Baumert K, et al. The clinical significance of platelet-associated IgG: a study of 298 patients with various disorders. Br J Haematol 1980; 46: 123-31.

19 Beztrovnaja LA, Polozij EA, Doksina GA. The influence of protein on the change in taurine concentration and on the SHgroups in the thrombocytes of irradiated rats. Radiobiol Radiother (Berl) 1980; 2: 162-7. 